\title{
'THE RIGHT TO BE FORGOTTEN' AND THE SUI GENERIS CONTROLLER IN THE CONTEXT OF CJEU JURISPRUDENCE AND THE GDPR
}

\author{
Nina Gumzej*
}

\begin{abstract}
The Google Spain judgment established a search engine as a sui generis controller and the related 'right to be forgotten' (right to delisting) under data protection legislation, despite the controversies surrounding it primarily on account of the logic of the search engine operator's functioning and its consequent inability to comply with certain basic data protection requirements. Resulting interpretations, ie the contouring of data protection legislation under CJEU case law (the Google Spain and the GC and Others judgment), are examined in this paper in detail in relation to the currently applicable GDPR provisions, which allows conclusions to be drawn on the substance of the (sui generis) delisting right, the legal standing of data subjects, the assessment of delisting requests, and the related role and responsibilities of search engine operators. While neither removal from the source web page is required nor can delisting be denied exclusively on the basis of the publisher's right to freedom of information and expression, analysis shows several manifestations of inherent interweavement with concerns of freedom of information and expression, which at the same time intrinsically oppose data protection and privacy rights. The issue is further challenged by a lack of harmonisation in the area of reconciling privacy and data protection rights with the freedom of expression and information. The last section of the paper discusses the rationale behind the recently established duty of adjusting, ie rearranging, search results in certain cases where delisting requests were denied, the implications for the operators, and the future outlook.
\end{abstract}

Keywords: right to be forgotten, GDPR, GC and Others $v$ CNIL, sensitive data, legitimate interest, substantial public interest, freedom of information, adjusting search results

\section{Introduction}

The Court of Justice of the EU first examined the role of internet search engines in the dissemination of information relating to individuals in the EU as well as in disabling accessibility thereof in its 2014 milestone judgment on the 'right to be forgotten' (hereinafter: Google

\footnotetext{
"Associate Professor, Chair of Information Technology Law and Informatics, University of Zagreb Faculty of Law, ngumzej@pravo.hr (ORCID iD: 0000-0002-7434-3538). DOI: 10.3935/cyelp.17.2021.447.
} 
Spain judgment). ${ }^{1}$ There the Court interpreted the application of EU data protection law requirements (ie the then applicable Data Protection Directive $^{2}$ ) to the search engine operator in relation to the personal data of individuals in the EU (data subjects) ${ }^{3}$ that it indexes and makes available in its search results. In the context of the right to seek the erasure of personal data and the right to object to their processing under EU data protection law, the Court affirmed the data subject's right to request that the search engine operator cease to include in search results, returned following a search query based on their name, links to third-party web pages where relevant data were published. That right is contingent on reasons of the (earlier or present) incompatibility of such inclusion of data by operators with the Data Protection Directive ${ }^{4}$ and exists independently of the establishment of prejudice made to the data subject as well as where the data were lawfully published and previously or simultaneously not removed from source third-party web pages. ${ }^{5}$

A careful analysis specific to each delisting request is required in the process of assessment, which must include the balancing of the data subject's fundamental rights to privacy and personal data protection (Arts 7 and 8 of the Charter of Fundamental Rights of the European Union, hereinafter: Charter) with the interest of the public in accessing relevant data through a specific search query based on the data subject's name (freedom of information, Art 11 of the Charter6). The elements in that assessment include on one hand the nature of the information in

\footnotetext{
${ }^{1}$ Case C-131/12 Google Spain SL and Google Inc. v Agencia Española de Protección de Datos (AEPD) and Mario Costeja González ECLI:EU:C:2014:317 (Google Spain judgment).

${ }^{2}$ Directive 95/46/EC of the European Parliament and of the Council of 24 October 1995 on the protection of individuals with regard to the processing of personal data and on the free movement of such data [1995] OJ L281/31 (hereinafter: Data Protection Directive or DPD). This directive was repealed by the General Data Protection Regulation (hereinafter: GDPR) Regulation (EU) 2016/679 of the European Parliament and of the Council of 27 April 2016 on the protection of natural persons with regard to the processing of personal data and on the free movement of such data, and repealing Directive 95/46/EC (General Data Protection Regulation) [2016] OJ L119/1, Corrigendum [2018] OJ L127/2.

${ }^{3}$ Personal data are any information relating to an identified or identifiable natural person ('data subject'). See Art 2(a) DPD. cf Art 4(1) GDPR.

${ }^{4}$ Thus, Lynskey argued already in 2015 that a "critical distinction between, on the one hand, the right to erasure if processing is incompatible with the provisions of the Directive and, on the other, a right to be forgotten based on an individual's personal preferences has not been adequately recognised and has enabled the judgment's implications to be exaggerated'. Orla Lynskey, 'Control over Personal Data in a Digital Age: Google Spain v AEPD and Mario Costeja Gonzalez' (2015) 78 Modern Law Review 522, 528.

${ }^{5}$ See Google Spain judgment (n 1) paras 84, 93-96.

${ }^{6}$ While in the Google Spain judgment the Court did not explicitly refer to Art 11 of the Charter but to the noted interest of the public, this was 'rectified' in its subsequent judgment. See Case C-136/17 GC and Others $v$ Commission nationale de l'informatique et des libertés (CNIL) ECLI:EU:C:2019:773 (hereinafter: GC and Others judgment) paras 66, 68-69, 75 and 79.
} 
question and its sensitivity for the data subject's private life, and, on the other hand, the interest of the public in having that information, interest which may vary according to the role played by the data subject in public life. ${ }^{7}$ In implementation of the requirements set by the CJEU in its ruling and in particular the balancing of relevant rights and freedoms, Google established a team of independent experts to help interpret the requirements of the ruling when examining requests for delisting. ${ }^{8}$ At the EU level, the Article 29 Data Protection Working Party issued its guidelines to ensure consistent implementation of the ruling within the EU, ${ }^{9}$ and more recently the European Data Protection Board (hereinafter: EDPB) issued the first part of the "Guidelines on the Criteria of the Right to be Forgotten in the Search Engine Cases under the GDPR'. ${ }^{10}$

Despite the positive responses and wide acclaim, the Google Spain judgment was (at least initially) perceived as highly controversial on account of the seemingly greater emphasis placed on privacy and data protection rights than on the online right to freedom of information. Particularly by the media, it was marked as the legitimisation of censorship and as a significant threat to online freedom of speech, and was thus also reported as 'a retrograde move that misunderstands the role and responsibility of search engines and the wider internet', ${ }^{11}$ 'astonishing, ${ }^{12}$ 'preposterous', ${ }^{13}$ 'misbegotten', 'technologically clueless', ${ }^{14}$ and an 'all round horrible' ruling making search engines 'responsible for making

\footnotetext{
${ }^{7}$ See Google Spain judgment (n 1) paras 81, 97 and 99. ef GC and Others judgment (n 6) paras 53 and 66.

8 'The Advisory Council to Google on the Right to be Forgotten' (Google Advisory Council, 6 February 2015) <www.google.com/advisorycouncil/> accessed 30 June 2021.

${ }_{9}^{9}$ Article 29 Data Protection Working Party, 'Guidelines on the Implementation of the Court of Justice of the European Union Judgment on "Google Spain and inc v Agencia Española de Protección de Datos (AEPD) and Mario Costeja González" C-131/12' 14/EN, WP 225, 26 November 2014.

${ }^{10}$ European Data Protection Board (EDPB), 'Guidelines 5/2019 on the Criteria of the Right to be Forgotten in the Search Engine Cases under the GDPR (part 1)', version 2.0, 7 July 2020.

${ }^{11}$ Index on Censorship, 'Index Blasts EU Court Ruling on the "Right to Be Forgotten"' (Index on Censorship, 13 May 2014) <www.indexoncensorship.org/2014/05/index-blasts-eucourt-ruling-right-forgotten> accessed 30 June 2021.

12 Dave Lee, 'Google Ruling “Astonishing”, Says Wikipedia founder Wales' (BBC News, 14 May 2014) <www.bbc.com/news/technology-27407017> accessed 30 June 2021.

${ }^{13}$ Stewart Baker, 'Contest! Hacking the Right to Be Forgotten' The Washington Post (Washington 7 June 2014) <www.washingtonpost.com/news/volokh-conspiracy/wp/2014/06/07/ contest-hacking-the-right-to-be-forgotten> accessed 30 June 2021.

${ }^{14}$ Claude Barfield, 'The Misbegotten 'Right to Be Forgotten” (US News \& World Report, 5 December 2014) <www.usnews.com/debate-club/should-there-be-a-right-to-be-forgottenon-the-internet/the-misbegotten-right-to-be-forgotten> accessed 30 June 2021.
} 
stuff disappear from the internet, even if that information is accurate. ${ }^{15}$ Unsurprisingly, the judgment and overall concept of 'the right to be forgotten' have up until today raised significant interest in academia, ${ }^{16}$ including my own. ${ }^{17}$ However, the approach to their 'unveiling' has neither been straightforward nor unanimous, and there have been criticisms, ${ }^{18}$ among other things, due to the obscurity of the goals toward data privacy or dignitary privacy protection. ${ }^{19}$ In particular, there was criticism in literature on the CJEU's approach to the balancing of rights and freedoms, specifically the lacking references to Art 11 of the Charter on the freedom of expression and information, Art 52(1) of the Charter on limitations of the rights and freedoms, as well as Art 52(3) thereof in connection with the relevant case law of the European Court of Human Rights (ECtHR), where the scope and balance of related rights and freedoms under the European Convention on Human Rights are concerned. ${ }^{20}$

Added to the possibly elusive character is also the issue of different denotations of the 'right to be forgotten', even though this easily recognisable term remains prevalent. ${ }^{21}$ Terminology used in literature includes,

${ }_{15}$ Mike Masnick, 'Dangerous Ruling: EU Says Google Must Help People Disappear Stuff They Don't Like from the Internet' (Techdirt, 13 May 2014) <www.techdirt.com/articles/20140513/06385627215/dangerous-ruling-eu-says-google-must-help-people-disappear-stuff-they-dont-like-internet.shtml> accessed 30 June 2021.

${ }^{16}$ For example, see the database ("Notes on Academic Writings") kept by the CJEU in its case-law section (http://curia.europa.eu) on the Google Spain judgment.

17 Nina Gumzej, 'EU pravo na zaborav i globalni internet: izvršavanje zahtjeva za uklanjanje poveznica na pretraživačima' ['The EU Right to Be Forgotten and Global Internet: Enforcement of Delinking Requests'] (2016) 7 Media, Culture and Public Relations 171.

${ }^{18}$ For example, a concise overview of different critiques is available at Aleksandra Kuczerawy and Jef Ausloos, 'From Notice-and-takedown to Notice-and-delist: Implementing Google Spain' (2016) 14 Colorado Technology Law Journal 219, 229-233. For further criticisms relating to identified gaps/errors in the ruling, see eg David Forbes Lindsay, 'The "Right to Be Forgotten" by Search Engines under Data Privacy Law: A Legal and Policy Analysis of the Costeja Decision' in Andrew T Kenyon (ed), Comparative Defamation and Privacy Law (CUP 2016) 199; Scott D Goss, 'Data Protection Law Errors in Google Spain LS, Google Inc v Agencia Espanola de Proteccion de Datos, Mario Costeja Gonzalez' (Future of Privacy Forum, 4 September 2014) <fpf.org/2014/09/04/data-protection-law-errors-in-google-spain-lsgoogle-inc-v-agencia-espanola-de-proteccion-de-datos-mario-costeja-gonzalez/> accessed 30 June 2021.

${ }^{19}$ Robert C Post, 'Data Privacy and Dignitary Privacy: Google Spain, the Right To Be Forgotten, and the Construction of the Public Sphere' (2018) 67 Duke Law Journal 981.

${ }^{20}$ See eg Miquel Peguera, 'The Shaky Ground of the Right to Be Delisted' (2016) 18 Vanderbilt Journal of Entertainment \& Technology Law 507; Stefan Kulk and Frederik Zuiderveen Borgesius, 'Google Spain v González: Did the Court Forget About Freedom of Expression?' (2014) 3 European Journal of Risk Regulation 389; Eleni Frantziou, 'Further Developments in the Right to Be Forgotten: The European Court of Justice's Judgment in Case C-131/12, Google Spain, SL, Google Inc v Agencia Espanola de Proteccion de Datos' (2014) 14 Human Rights Law Review 761; Lynskey (n 4).

${ }^{21}$ Such a title was also explicitly codified in the context of the 'right to erasure' of personal data under Art 17 GDPR, according to which the data subject has the right to obtain from 
but is not limited to: the right to be delisted, ${ }^{22}$ to have links removed, ${ }^{23}$ to removal / to obscurity ${ }^{24}$ and/or to the suppression (of links to search engine results). ${ }^{25}$ In this paper, the concept of delisting is mainly used, though in my opinion all of the mentioned denotations reflect appropriately the technical aspects and manifestation or end result of a successful delinking request, which is not overall erasure (including removal from the index and cache of the search engine), but only the blocking of search results ${ }^{26}$ or making the data more difficult to find online. For instance, search queries not based on the name of the data subject would still render the links containing the data in question accessible in search results. ${ }^{27}$ Furthermore, the scope of delisting under the current interpretation of EU law is not universal (global), at least not by default. ${ }^{28}$ In any event, the relevant data do remain accessible, but they are no longer (en-

the controller the erasure of personal data concerning him or her without undue delay and the controller has the obligation to erase personal data without undue delay, under certain conditions (and subject to certain exceptions). Also, under Recital 65 GDPR, the right is relevant especially where consent to data processing online was earlier provided by the data subject as a child.

${ }^{22}$ See eg Article 29 Data Protection Working Party (n 9); Brendan Van Alsenoy and Marieke Koekkoek, 'Internet and Jurisdiction after Google Spain: The Extraterritorial Reach of the 'Right to Be Delisted” (2015) 5 International Data Privacy Law 105.

${ }^{23}$ See eg Hielke Hijmans, 'Right to Have Links Removed: Evidence of Effective Data Protection: Case C-131/12 Google v Agencia Española de Protectión de Datos (AEPD) and Mario Costeja Gonzalez, Judgment of 13 May 2014' (2014) 21 Maastricht Journal of European and Comparative Law 555.

${ }^{24}$ See eg David Hoffman, Paula Bruening and Sophia Carter, 'The Right to Obscurity: How We Can Implement the Google Spain Decision' (2016) 17 North Carolina Journal of Law \& Technology 437. Also, according to Uncular: 'Google Spain can merely invent a right to removal or right to obscurity at the most rather than a right to erasure let alone a right to be forgotten'. Selen Uncular, 'The Right to Removal in the Time of Post-google Spain: Myth or Reality under the General Data Protection Regulation?' (2019) 33 International Review of Law, Computers \& Technology < https://doi.org/10.1080/13600869.2018.1533752> accessed 30 June 2021.

${ }^{25}$ Christopher Kuner, 'The Court of Justice of the EU Judgment on Data Protection and Internet Search Engines: Current Issues and Future Challenges' in Burkhard Hess and Cristina M. Mariottini (eds), Protecting Privacy in Private International and Procedural Law and by Data Protection (Ashgate/Nomos, 2015) 19; Yann Padova, 'Is the Right to Be Forgotten a Universal, Regional, or “Glocal” Right?' (2019) 9 International Data Privacy Law 15.

${ }^{26}$ EDPB (n 10) 12 (point 49).

${ }^{27}$ See eg Google France Sarl, 'Submission for Isabelle Falque-Pierrotin', 31 July 2014, points 12-14 <docs.google.com/a/google.com/file/d/OB8syaai6SSfiTOEwRUFyOENqR3M/ preview?pli=1 > accessed 30 June 2021; Commission, 'Mythbusting, the Court of Justice of the EU and the "Right to be Forgotten"' (Commission, 18 September 2014) <http://ec.europa.eu/justice/data-protection/files/factsheets/factsheet_rtbf_mythbusting_en.pdf> accessed 2 August 2015; EDPB (n 7) 5 (points 8-9).

${ }^{28} \mathrm{EU}$ law does not prescribe a duty to conduct delisting on all domain versions of the search engine, ie globally. Case C-507/17 Google LLC v Commission nationale de l'informatique et des libertés - CNIL ECLI:EU:C:2019:772. 
tirely) ubiquitous, which is, in the words of the European Commission, 'enough for the citizen's privacy to be respected'. ${ }^{29}$

This paper is a contribution towards the decoding of the earlier noted vagueness that might surround the right to delisting, which is primarily based on an analysis and assessment of CJEU judgments in Google Spain and the subsequent, more recent, GC and Others case, ${ }^{30}$ together with the applicable legislation, which is primarily the currently applicable General Data Protection Regulation (hereinafter also: GDPR). ${ }^{31}$ This will allow conclusions to be drawn on the substance of the right, the legal standing of data subjects, the assessment of delisting requests, and the related specific role and responsibilities of search engine operators.

The analysis in the paper revolves around several premises. The first one explored as of the next section is that the Google Spain judgment established a sui generis controller and the related delisting right, despite the controversies surrounding it primarily on account of the operator's basic functioning, since it has no knowledge or control over the online information that it indexes and refers to the public via links displayed in search results. Furthermore, since the delisting right is founded on data protection legislation, specifically on the rights to object and seek personal data erasure, it is invoked and assessed primarily in the context of that legislation, subject to interpretations by the CJEU. As a sui generis right, it requires neither proof of prejudice being made to data subjects in order to be invoked, nor the establishment of the illegality of the relevant publication and removal from the source web page. It also cannot be denied exclusively on the basis of the publisher's potentially prevailing right to freedom of information and expression. The third section is the main one in this paper, and is thematically divided into several sections. This analysis will start with an exploration of the premise that for the reasons mentioned above, the operator as controller is unable to comply with the basic data protection requirements arising from the "know thy data' postulate. While this normally has its consequences under data protection legislation, they do not for particular reasons apply to this (sui generis) controller. A separate issue examined considers the operator's mission of making information universally accessible and useful; ${ }^{32}$ by doing so, the operator fulfils the role of information intermediary be-

\footnotetext{
${ }^{29}$ Commission, 'Factsheet on the "Right to Be Forgotten" Ruling C-131/12' <http://ec.europa.eu/justice/data-protection/files/factsheets/factsheet_data_protection_en.pdf accessed> accessed 2 August 2015.

${ }^{30} \mathrm{GC}$ and Others judgment (n 6).

${ }^{31}$ GDPR (n 2).

32 'Our company mission is to organize the world's information and make it universally accessible and useful (...). To keep information openly accessible, we only remove content from our search results in limited circumstances, such as compliance with local laws or site
} 
tween data producers (publishers) and data users. Thus, the function and responsibilities of the controller under data protection legislation inherently involve and affect freedom of information and expression, which is at the core not only of its own function and the interest of its users searching for relevant information, but also that of publishers aiming to make their published information visible and widely disseminated via the search engine. In this context, the premise further examined is that of the fundamental functional interweaving of the delisting right with the freedom of information and expression concerns, which intrinsically oppose data protection and privacy rights. In this context, it will also be assessed whether, and if so to what extent, EU law recognises the mentioned interests and, if it does, whether any hierarchy is, or might be and should be, afforded between them. Given that, of the superabundant personal data indexed and referred to in search results, it is the sensitive data that are afforded strongest protection, the paper will examine and discuss available mechanisms for ensuring such protection under EU law, as adjusted (contoured) to the particular function, powers and responsibilities of the search engine operator. The last section prior to the concluding remarks discusses the benefits and dangers of the extraordinary novel duty of operators to rearrange search results in particular cases where delisting requests have been denied.

\section{Setting the scene: the sui generis controller and other distinctive features of the delisting right}

In interpreting the application of EU data protection legislation to the Google search engine, the CJEU affirmed in the Google Spain judgment both its material ${ }^{33}$ and territorial ${ }^{34}$ scope of application. In focus here is the Court's analysis of its material scope of application that led to its qualification of relevant search engine activities (finding information published or placed on the internet by third parties, indexing it automatically, storing it temporarily and making it available to internet users according to a particular order of preference) as personal data processing. ${ }^{35}$

Moving on to the critical issue of whether the search engine operator can be qualified as the controller who determines the purposes and means of such processing and who is responsible therefor, the Court

owner requests'. Google Search, 'Our Approach to Search' <google.com/search/howsearchworks/mission/> accessed 30 June 2021.

${ }_{33}$ Google Spain judgment (n 1) paras 21-41.

${ }^{34}$ ibid, paras 42-60.

35 ibid, paras 27-31, 41. For definitions relating to personal data processing, see Art (2)(a) and Art (2)(b) DPD. cf Art 4(1) and art (4)(2) GDPR. 
found that the operator does fit the prescribed definition, ${ }^{36}$ as further supported by teleological argumentation ${ }^{37}$ and by the application of the principle of proportionality. ${ }^{38}$ As to the latter, while acknowledging the differing data processing activities of publishers loading relevant data on the website and of operators providing links to them upon a namebased search query, ${ }^{39}$ the Court found that the processing activities of the latter may affect the rights to privacy and data protection even more than those of the publisher. This is on account of their pivotal role in the online dissemination and presentation of personal data (profiling) for all internet users undertaking a relevant name-based search query. ${ }^{40}$

The Court appears to have acknowledged Google's submissions that the search engine operator has no knowledge and control over the personal data published on third-party websites; however, this was not a relevant factor for its decision on Google as the controller. Conversely, it was for those reasons that the AG argued ${ }^{41}$ that the operator could not be the controller, ie taking into account its intermediary function and lack of control over data published on third-party sites, and the consequent inability to both discern between personal and other data as well as to comply with the basic data protection requirements. ${ }^{42}$ All that led to the AG's conclusion that should search engines be qualified as controllers,

${ }^{36}$ Google Spain judgment (n 1) paras 32-41. For a definition of the controller, see Art 2(d) DPD. cf Art 4(7) GDPR.

${ }^{37}$ Google Spain judgment (n 1) para 34.

${ }^{38}$ Paul de Hert and Vagelis Papakonstantinou, 'Google Spain: Addressing Critiques and Misunderstandings One Year Later' (2015) 22 Maastricht Journal of European and Comparative Law 624, 627.

${ }^{39}$ Google Spain judgment (n 1) para 35.

40 ibid, paras 36-37, 87. Already in early literature following the judgment it was argued that 'search engines arguably make a distinct and substantial contribution to the existing knowledge base, which positively adds to the public's right to access information under Article 11 and can be considered as creating a novel subset of protected expression'. Frantziou (n 20) 769.

41 'Opinion of Advocate General Jääskinen', 25 June 2013, ECLI:EU:C:2013:424, paras 83, 85, 88 and 89. The AG supported his arguments with the Article 29 Data Protection Working Party non-binding interpretative opinions and recital 47 of the Data Protection Directive. As regards the former, see in particular 'Opinion $1 / 2008$ on data protection issues related to search engines', 00737/EN, WP 148, 4 April 2008 (in particular 13-14); 'Opinion 1/2010 on the concepts of "controller" and "processor", 00264/10/EN, WP 169, 16 February 2010.

${ }^{42}$ In his analysis, the AG raised a number of important issues such as those on the regulation of internet search engines in their role of information location tool providers and of intermediaries' liability regime under the e-Commerce Directive (Directive 2000/31/EC of the European Parliament and of the Council of 8 June 2000 on certain legal aspects of information society services, in particular electronic commerce, in the Internal Market [2000] OJ L178/1) as well as the issue of their inability to fulfil, in the role of controllers, the basic requirements of the Data Protection Directive (eg data quality principles and legal bases for processing). AG Opinion (n 41) paras 84-100. 
their operations would be deemed illegal under EU data protection law, ${ }^{43}$ subject to certain exceptions. The exception where the operator could be considered the controller is, according to the AG, ${ }^{44}$ where it ignored or disobeyed a request of the publisher (website administrator) not to make those data available for dissemination through the search engine, or where it ignored or disobeyed the publisher's request to update the cache memory (thereby, for example, continuing to show the data erased by the publisher) ${ }^{45}$ However, again not following the AG's Opinion, the CJEU held that this was not a condition for establishing the search engine's responsibility for data processing in the context of its own data processing activities. ${ }^{46}$

The substantial differences between the AG's Opinion and the CJEU regarding the qualification of a search engine operator as a controller were highlighted and discussed in literature, with some authors siding with (and expanding on) the AG's arguments ${ }^{47}$ and others arguing that search engine operators can and/or should be controllers. ${ }^{48}$ In contrast to the AG's extensive analysis of the issue, the CJEU's reasoning was very sparse on that critical point, thereby allowing further critiques and discussions on that evidently not entirely clear legal-technology issue. ${ }^{49}$

\footnotetext{
${ }^{43}$ AG Opinion (n 41) para 90.

${ }^{44}$ ibid, paras 91-93, 99.

${ }^{45}$ This is taking into account that the publishers can technically ensure that the data they publish are made unavailable to search engines, eg via exclusion protocols such as 'robot. txt' or codes such as 'noindex' or 'noarchive'. Google Spain judgment (n 1) para 39. According to subsequently issued guidelines by the Article 29 Data Protection Working Party on the implementation of this ruling, the data subject may himself/herself request this from the publisher, but that is not decisive. Article 29 Data Protection Working Party (n 9) 6-7 (point 11).
}

${ }^{46}$ Google Spain judgment (n 1) para 39. There could potentially be joint controllership in such cases. See Google Spain judgment (n 1) para 40.

${ }^{47}$ For detailed analyses supporting that position, see eg Giovanni Sartor, 'Search Engines as Controllers: Inconvenient Implications of a Questionable Classification' (2014) 21 Maastricht Journal of European and Comparative Law 564; Peguera (n 20).

${ }^{48}$ For a detailed analysis, see de Hert and Papakonstantinou (n 38). These authors also provide an interesting perspective on the qualification of the search engine as controller by reason of Google's search algorithm success, which distinguishes that operator from its competitors. Given that it may be challenged if other, for example less successful, search engines (the degree in the overall dissemination of information) qualified as controllers, the Court should have based its qualification of that search engine as a controller on the technical aspects of the search engine's functioning rather than on proportionality, ie the significance of (that) search engine for the overall dissemination of information. ibid 626-28. Frantziou also discusses the impact of the Google Spain judgment in respect to its broad construction of the controller in an online environment, in particular as regards the unclear scope of responsibilities deriving therefrom, and called for better legal clarity in that respect. Frantziou (n 20) 770-72.

${ }^{49}$ For example, according to Bassini, the 'judgment is not entirely convincing on this point, being inspired more by the purpose of reassuring individuals that their personal data will 
While the CJEU has not approached that issue further in its subsequent judgments, ${ }^{50}$ it can well be assumed that its rationale on the concept of the controller from the Google Spain judgment remains valid also under the currently applicable GDPR. ${ }^{51}$ As such, that rationale is at the heart of data subjects' standing against search engine operators as far as their data protection rights are concerned, and the operators as controllers cannot avoid related responsibility. On the other hand, even though the operator's lack of knowledge and control over data published on third-party websites was not a relevant factor for its qualification of the Google search engine operator as the controller, the Court incorporated the consequences thereof for compliance with the EU data protection framework into the so-called responsibility doctrine. ${ }^{52}$ To be more precise, it held that the search engine operator in its role of controller must assume responsibility and ensure compliance with the EU data protection framework, although within the framework of its 'responsibilities, powers and capabilities'. ${ }^{53}$ Consequently, the Court's establishment of a search engine operator as a sui generis controller, with the resulting tailoring of relevant data protection obligations according to its responsibilities, powers and capabilities, ${ }^{54}$ constitutes the first distinctive feature of the right to delisting under EU law.

The second distinctive feature is the established right to exercise (the right to) delisting against search engine operators regardless of and independently of an individual's exercise of the more traditional legal

not be affected by the processing through search engines rather than a comprehensive analysis on whether all the elements of the definition controller are met'. Marco Bassini, 'Data Controller: A Shifting Paradigm in the Digital Age' (2019) 13 Bocconi Legal Papers 103, 114.

${ }^{50}$ GC and Others judgment (n 6); Google LLC (n 28).

${ }^{51}$ The concept of controller according to the EDPB is not only functional but also autononous 'in the sense that, although external legal sources can help identifying who is a controller, it should be interpreted mainly according to EU data protection law. The concept of controller should not be prejudiced by other - sometimes colliding or overlapping - concepts in other fields of law, such as the creator or the right holder in intellectual property rights or competition law'. Furthermore, the concept must be 'intepreted in a sufficiently broad way, favouring as much as possible effective and complete protection of data subjects (...) so as to ensure full effect of EU data protection law, to avoid lacunae and to prevent possible circumvention of the rules (...)'. EDPB, 'Guidelines 07/2020 on the concepts of controller and processor in the GDPR', version 2.0., 7 July 2021, 9 (points 13-14).

${ }^{52}$ According to Quelle, the responsibilities doctrine was 'developed so as to maintain a wide scope of application while keeping the consequences of controllership in check'. Claudia Quelle, 'GC and Others v CNIL on the Responsibility of Search Engine Operators for Referring to Sensitive Data: The End of 'Right to Be Forgotten' Balancing?' (2019) 5 European Data Protection Law Review (EDPL) 438, 440.

${ }^{53}$ Google Spain judgment (n 1) paras 38 and 83.

${ }^{54}$ The mentioned points were reiterated in the subsequent GC and Others judgment (n 6) paras 35-37. 
institutes against publishers directly (eg to have published information removed directly from the source). To be more precise, a search engine can be ordered to remove the data from search results even where such data were lawfully published on the source (third party's) web page and even where they were not previously or simultaneously removed from the source web page. The Court issued this finding in response to several considerations, all of which are based on reasons of 'effective and complete protection of data users, ${ }^{55,56}$ One is the previously noted consideration of the significantly easier access to relevant information by use of a search engine (name-based search query) and on the resulting ubiquity of such data, which may constitute more significant interference with the data subject's right to privacy than the publication of the data on the publisher's web page. The other is the potential inability of data subjects to succeed in obtaining their data removal online for reasons of the technical ease of online data reproduction and jurisdictional issues should the publisher not be subject to EU law. The third is that the publishers may under their respective national laws benefit from the prevailing higher regard to the interest of freedom of information and therefore keep relevant published information online. ${ }^{57}$ Furthermore, publishers may by application of their respective law have the right to keep data online as was the case in respective national proceedings, where the publication of the data was prescribed by law and owing to which the publisher was not bound to take the data down (or alter them, or technically render the data inaccessible to search engines).

All of the issues described here should be considered as leitmotifs in the ensuing detailed analysis of the different aspects and concerns relating to the implementation of the right to delisting in light of the applicable rules and CJEU jurisprudence.

\footnotetext{
${ }_{55}$ Data subjects, presumably.

${ }^{56}$ Google Spain judgment (n 1) paras 82, 84-88.

${ }^{57}$ Under Art 9 DPD ('Processing of personal data and freedom of expression') Member States shall provide for exemptions or derogations from the provisions of this Chapter, Chapter IV and Chapter VI for the processing of personal data carried out solely for journalistic purposes or the purpose of artistic or literary expression only if they are necessary to reconcile the right to privacy with the rules governing freedom of expression. See additionally recitals 17, 37 DPD. Similarly, the current Art 85 GDPR specifies that it is for the Member States, in particular as regards processing undertaken solely for journalistic purposes or for the purpose of artistic or literary expression, to provide for the exemptions and derogations necessary to reconcile those rights with, inter alia, freedom of information. See also Art 85(2) as well as recital 153 GDPR.
} 


\section{Placing delisting requests under the (strict) scope of the law}

\subsection{The legal basis and involved rights}

Since any data processing must have a legal basis under data protection law, the CJEU established that of 'legitimate interest' as the applicable basis for a search engine's data processing activities, ${ }^{58}$ which applies also under the currently applicable GDPR. The basis applies to the extent that such legitimate interests are not overridden by the interests or fundamental rights and freedoms of the data subject which require protection of personal data, in particular where the data subject is a child'. ${ }^{59}$ In all cases where the data processing is based on legitimate interest, data subjects have a specific right to object to such processing, which also applies in terms of the currently applicable GDPR. ${ }^{60}$ However, in contrast to the earlier Directive, the GDPR affords increased protection for data subjects, since it shifted the burden of demonstrating the compelling legitimate grounds to the controller. To be more precise, data subjects can by objection invoke at any time the grounds relating to their particular situation, and it is the search engine operator that now needs to prove that it has compelling legitimate grounds for the processing, which override the above-mentioned interests, rights and freedoms of the data subject. ${ }^{61}$

Whilst being a logical option toward the 'legitimisation' of the search engine's data processing activities (once they were established suigeneris controllers), the legitimate interest basis also allowed those operators to

\footnotetext{
${ }^{58}$ Google Spain judgment (n 1) paras 73-74. The legitimate interest basis was prescribed in Art $7 f$ DPD.

59 Under Art 6(1) GDPR, the processing 'shall be lawful only if and to the extent that at least one of the following applies: (...) (f) processing is necessary for the purposes of the legitimate interests pursued by the controller or by a third party, except where such interests are overridden by the interests or fundamental rights and freedoms of the data subject which require protection of personal data, in particular where the data subject is a child'.

${ }^{60}$ Art 21(1) GDPR specifies (1st sentence): 'The data subject shall have the right to object, on grounds relating to his or her particular situation, at any time to processing of personal data concerning him or her which is based on point (e) or (f) of art 6(1), including profiling based on those provisions'. Namely, Art 6 GDPR prescribes legal bases for the processing. The first (Art 6(1)(f)) is noted above (ibid) and the second (Art 6(1)(e)) is the necessity of processing for the "performance of a task carried out in the public interest or in the exercise of official authority vested in the controller'.

${ }_{61}$ 'The controller shall no longer process the personal data unless the controller demonstrates compelling legitimate grounds for the processing which override the interests, rights and freedoms of the data subject or for the establishment, exercise or defence of legal claims'. Art 21(1) GDPR (2nd sentence). In connection with this, see also GDPR recital 69. Under Art 14 DPD, data subjects needed to base their objections on compelling legitimate grounds relating to their particular situation. See also EDPB (n 10) 8-9 (points 28-30).
} 
continue their operations "normally'62 (ie without prior monitoring) up until a delisting request, which would then prompt the subsequent data protection compliance check-up. On account of their capabilities and responsibilities discussed in the previous section, search engine operators are unable to conduct any prior balancing test in respect of their legitimate interest processing grounds, but rather a specific test ${ }^{63}$ is to be made upon a delisting request. This test should ensure specific consideration of the data subject's particular situation and circumstances. ${ }^{64}$ As for the data subjects that request delisting, it could be argued that on account of the operator's default legitimate interest basis for the processing, they can object to such processing (ie request delisting) by default, and on the basis of their particular situation (a right which under the GDPR also affords them increased protection due to the earlier noted shifted burden of proof to the operator).

Where legitimate grounds are not established, and whilst it could be deduced that already then the links to the data in question should immediately be blocked from the relevant search results, ${ }^{65}$ provisions on the right to erasure come into play, as well as the related exceptions that include the freedom of expression and information. At first glance this might seem confusing, in particular since the right to delisting does not result in the erasure of relevant personal data from the operator's index or cache (and certainly not from the source third-party's website). ${ }^{66}$ However, erasure in the context of the sui generis controller and delisting right is manifested by the removal of links from those search results, which are presented after a search has been made on the basis of the data subject's name. In any case, and most importantly, the GDPR now expressly links the right of data subjects to seek the erasure of their personal data (ie delisting) in connection with the exercised right to objection. ${ }^{67}$ In other words, the data are to be delisted in cases where, upon objection, the operator did not demonstrate compelling legitimate

\footnotetext{
62 'In the light of the potential seriousness of that interference, it is clear that it cannot be justified by merely the economic interest which the operator of such an engine has in that processing. Google Spain judgment (n 1) para 81. Additionally see Google Spain judgment (n 1) points 97, 99.

${ }^{63}$ Article 29 Data Protection Working Party, 'Opinion 06/2014 on the notion of legitimate interests of the data controller under Article 7 of Directive 95/46/EC', 844/14/EN, WP 217, 9 April 2014, 9.

${ }^{64}$ Google Spain judgment (n 1) para 76.

${ }^{65}$ Art 21(1) GDPR, 2nd sentence (n 61).

${ }^{66}$ EDPB (n 10) 5 points 8-9.

${ }^{67}$ Under Art 17(1)(c) GDPR, 'the data subject shall have the right to obtain from the controller the erasure of personal data concerning him or her without undue delay and the controller shall have the obligation to erase personal data without undue delay' where 'the data subject objects to the processing pursuant to Article 21(1) and there are no overriding legitimate grounds for the processing (...)'.
} 
grounds for the processing, which override the interests, rights and freedoms of the data subject (Art 21(1) GDPR)) ie where there are no overriding legitimate grounds for the processing (Art 17(1)(c) GDPR)). ${ }^{68}$

Data subjects also have the right to seek data erasure under other prescribed circumstances in the GDPR, ${ }^{69}$ inter alia where those data are no longer necessary in relation to the purposes for which they were collected or otherwise processed, or where they were unlawfully processed. Data subjects may always invoke such multiple grounds for delisting, ie in addition to the exercised right to object. ${ }^{70}$

The right to erasure is, however, not absolute, since exceptions from the duty to erase apply also in the context of assessing delisting requests. ${ }^{71}$ Consequently, such exceptions apply also in cases where the operator did not demonstrate compelling legitimate grounds for the processing, which override the interests, rights and freedoms of the data subject (Art (21)(1) GDPR)) ie where there are no overriding legitimate grounds for the processing (Art (17)(1)(c) GDPR)) and in other relevant cases that would otherwise prompt delisting, in particular where the processing was unlawful. ${ }^{72}$ Out of those exceptions, most notable in the context of the search engine operator as a sui generis controller aiming

\footnotetext{
${ }_{68}$ 'Indeed, the application of Article 21 is expressly foreseen as the third ground for the Right to erasure. As a result, both Article 17 and Article 21 GDPR can serve as a legal basis for delisting requests'. EDPB (n 10) 5 (point 5).
}

${ }^{69}$ Art 17 GDPR contains more comprehensive provisions on the right to erasure in relation to DPD (Art 12b), specifying in para 1 the grounds for seeking erasure, as follows: '(a) the personal data are no longer necessary in relation to the purposes for which they were collected or otherwise processed; (b) the data subject withdraws consent on which the processing is based according to point (a) of Article 6(1), or point (a) of Article 9(2), and where there is no other legal ground for the processing; (c) the data subject objects to the processing pursuant to Article 21(1) and there are no overriding legitimate grounds for the processing, or the data subject objects to the processing pursuant to Article 21(2); (d) the personal data have been unlawfully processed; (e) the personal data have to be erased for compliance with a legal obligation in Union or Member State law to which the controller is subject; (f) the personal data have been collected in relation to the offer of information society services referred to in Article 8(1)'.

${ }^{70}$ EDPB (n 10) 6-7 (point 16).

${ }^{71}$ Under Art 17(3) GDPR the right to erasure shall not apply: 'to the extent that processing is necessary: (a) for exercising the right of freedom of expression and information; (b) for compliance with a legal obligation which requires processing by Union or Member State law to which the controller is subject or for the performance of a task carried out in the public interest or in the exercise of official authority vested in the controller; (c) for reasons of public interest in the area of public health in accordance with points (h) and (i) of Article 9(2) as well as Article 9(3); (d) for archiving purposes in the public interest, scientific or historical research purposes or statistical purposes in accordance with Article 89(1) in so far as the right referred to in paragraph 1 is likely to render impossible or seriously impair the achievement of the objectives of that processing; or (e) for the establishment, exercise or defence of legal claims'.

${ }^{72}$ If, for example, the operator failed to prove its legitimate interest basis for processing. EDPB (n 10) 10 (point 36). 
to make published data universally accessible ${ }^{73}$ is the one on the freedom of expression and information, at the core of which lies the requirement of establishing a balance between competing rights to privacy and data protection with the freedom of information.

While the mentioned freedom of information and expression exception from the right to erasure, which may justify the refusal of a delisting (erasure) request, has only been enacted more recently in the GDPR, the CJEU approached the same issue in its Google Spain judgment from the point of view of exemptions or derogations from rights and obligations under the DPD (and thus also from the duty to delist personal data). It confirmed that such exemptions and derogations include in particular situations where the relevant personal data are processed for journalistic purposes (Art 9 DPD, which is now similarly reproduced in Art 85 $\mathrm{GDPR}^{74}$ ). However, unlike data publishers, search engine operators 'appear' ineligible to benefit from such exemptions and derogations under their respective national legislation. ${ }^{75}$ In fact, as noted in the previous section, the mentioned exemptions and derogations afforded to publishers constituted the Court's arguments towards its establishment of the right to exercise the right to delisting against operators, regardless of and independently of the exercise of more traditional legal institutes against publishers directly. ${ }^{76}$

The same delineation between the operator's and data publisher's processing activities and the possibly different consequences thereof in delisting cases (as established in the Google Spain judgment) apply also in respect of the here examined GDPR provision on the right to erasure and exceptions thereto. Furthermore, taking into account all of the examined GDPR provisions that are relevant in the context of a delisting request, including the default legitimate interest ground as a legal basis for the operator's processing activities, it is clear that its compelling legitimate grounds (to be checked upon the exercised delisting right) may include prescribed exceptions to the right to erasure and in particular that of the right of freedom of expression and information, which is at the heart of its function. ${ }^{77}$

\footnotetext{
${ }_{73}$ Google Search (n 32).

${ }^{74}$ See $\mathrm{n} 57$.

${ }^{75}$ Google Spain judgment (n 1) para 85.

${ }^{76}$ In that respect AG Szpunar observed, quite straightforwardly: 'That key passage from the judgment in Google Spain and Google (38) constitutes the hard core of the reasoning designed to justify the establishment of a "right to be forgotten": in order to protect the privacy and the right to the data of the data subject, it is possible to "shoot the messenger" (even) if a "rectification at source" is impossible, owing to the right to freedom of expression of a publisher of an internet page'. Opinion of Advocate General Szpunar delivered in Case 136/17, 10 January 2019, ECLI:EU:C:2019:14, para 81.
}

77 EDPB (n 10) 9 (point 30) and 11 (point 43). 
In consideration of the applicable GDPR provisions to delisting requests, the EPDB suggested the right to object as a more appropriate delisting basis than the right to erasure for both the search engine operator and the data subject. For data subjects, this is due to the limited prescribed grounds for invoking erasure, and for the operator it is due to the assessment that most of the exceptions to the duty of erasure (with the exclusion of the freedom of expression and information exception) appear inapplicable to them. ${ }^{78}$ This, for example, is the circumstance that the relevant data needed to be published under a Member State's law, ${ }^{79}$ which could not be relied on by the operator to reject the delisting (right to erasure) request, unless it was prescribed as a direct obligation toward search engine operators. ${ }^{80}$ On the other hand, that same circumstance would be considered at the stage of the balancing of rights, since it could support the freedom of information to easily access relevant data via a specific search query on the basis of the data subject's name. ${ }^{81} \mathrm{By}$ the same token, it is my opinion that while the operator could not deny a delisting request exclusively on account of the publisher's freedom of expression (ie the right to publish and keep published information online and, arguably, have its data easily accessible to internet users via search engine queries), the latter could be considered in the balancing of rights, ie toward the appraisal of internet users' freedom of information. I will discuss these issues in more detail in section 3.2.1 below.

\subsection{The regime for sensitive data}

The specific nature of the operator's data processing activities (ie indexing information and presentation of links to the data in search results following a query) and its restricted capabilities due to a lack of control over the published data leads to the conclusion that the nature of the data contained in the links provided in search results could not be checked in terms of the proper application of data protection legislation prior to such processing, but only afterwards, upon the data subject's notification, such as with a request for delisting. ${ }^{82}$ In terms of data pro-

$78 \mathrm{EDPB}$ (n 10) 8 (point 27) and 11 (point 43).

79 See art 17(3)(b) GDPR (n 71).

80 EDPB (n 10) 13 (points 55ff).

81 However, 'presumption of existence of a prevalent interest of the public does not operate in the same way in respect of the originating web pages compared to the results index of a search engine provider. Although the legal obligation to publish information on a certain web site may lead to the conclusion that this information should not be deleted from that web page, the decision regarding the results offered by the search engine provider when the name of a data subject is generally used as search term may be different'. EDPB (n 10) 14 (point 63).

${ }^{82}$ Thus, according to Van Alsenoy, it can be argued that Google Spain does not oblige search engine providers to exercise preventative control over the information it dissemi- 
tection compliance, the question then arises about whether there are any consequences for operators who include links to information containing sensitive personal data in the search results, and if so what they are. This is taking into account that following the Google Spain judgment it has become clear that search engine operators are in any case not going to be 'banned' from performing their essential information intermediary functions. The EU data protection legislation provides special protection for certain sensitive personal data. Firstly, there are the special categories of personal data, ${ }^{83}$ the processing of which is as a rule prohibited, unless certain very specific exceptions have been met, such as the data subject's explicit consent, the data being manifestly made public by the data subject, or the necessity of processing such data for reasons of substantial public interest on the basis of EU or Member State law. ${ }^{84}$ Thus, taking health data as an example, the inclusion of links to such data in search results is as a rule prohibited, unless the operator has complied with one of the prescribed exceptions. These exceptions, and in particular the applicability thereof to operators, will be examined further below. The second relevant category includes personal data relating to criminal convictions and offences, ${ }^{85}$ which may only be processed under the control of official authority or when the processing is authorised by EU or Member State law providing for appropriate safeguards for the rights and freedoms of data subjects. ${ }^{86}$

The earlier examined AG Opinion on the issue of whether search engine operators could be controllers ${ }^{87}$ provided the very example of the stricto sensu application of data protection rules to sensitive data (ie their processing would be unlawful) in support of the argument that such op-

nates. In fact, the reasoning of the CJEU suggests that the obligations of search engine providers concerning third-party data are essentially only "reactive": only after the provider has been made aware of the fact that the display of specific search results following a name search adversely impacts the data subject, must the provider assess whether or not delisting is necessary'. Brendan Van Alsenoy, Data Protection Law in the EU: Roles, Responsibilities and Liability (1st edn, Intersentia 2019) 548.

${ }^{83}$ These are "personal data revealing racial or ethnic origin, political opinions, religious or philosophical beliefs, or trade union membership, and the processing of genetic data, biometric data for the purpose of uniquely identifying a natural person, and the data concerning health or data concerning a natural person's sex life or sexual orientation'. Art 9(1) GDPR.

${ }^{84}$ For a full list, see Art 9(2) GDPR. cf Art 8(2) and Art 8(4) DPD.

${ }^{85}$ While these are not per se included in the definition of 'special categories of personal data' under EU data protection law, they are also considered sensitive and separate provisions regulating the otherwise restricted processing of such data. Art 10 GDPR. cf Art 8(5) DPD.

${ }^{86}$ An example of lawful processing of such data is where they were disclosed to the public by the public authorities in compliance with the applicable national law. GC and Others judgment (n 6) para 73.

${ }^{87}$ See section 2 above. 
erators could not be controllers. ${ }^{88}$ This specific concern regarding sensitive data was, however, not referred to in the Google Spain case, and the CJEU did not discuss it. In fact, despite the timely implementation of delisting practices in line with the Google Spain judgment, the concern was not on the CJEU menu in the course of the ensuing five years, ${ }^{89}$ all up to the here-examined GC and Others judgment. ${ }^{90}$ As noted in the previous section, in the Google Spain judgment the CJEU took into account the arguments that the operator in principle has no knowledge of and control over personal data published on third-party websites, but excluded it as irrelevant for its finding that such an operator is the controller, subject to data protection legislation, although with obligations to be assessed and applied in the framework of its specific responsibilities, powers and capabilities. By the same logic, and in interpretation also of the currently applicable GDPR, ${ }^{91}$ the Court rejected in the GC and Others judgment the operator's claim that the prohibition and restrictions relating to sensitive data processing should not apply to its processing activities at all. However, as construed on the basis of agreement with the AG and the Commission ${ }^{92}$ in respect of search engines' restricted responsibilities

\footnotetext{
${ }^{88}$ AG Opinion (n 41) para 90.

${ }^{89}$ As commented rightly by Leiser and Schermer, the question of what exception(s) Google was using has surprisingly never been answered. Mark Leiser and Bart Schermer, 'GC \& Others vs CNIL and Google: This Is a Special Case' (European Law Blog, 20 November 2019) $<$ https://europeanlawblog.eu/2019/11/20/gc-others-vs-cnil-and-google-this-is-a-specialcase/> accessed 30 June 2021.
}

${ }^{90} \mathrm{GC}$ and Others judgment (n 6). In the main proceedings, several persons made separate requests to Google to remove from search results based on their name information containing their sensitive personal data. These included a link leading to a satirical photomontage placed online pseudonymously; links leading to an article in the daily newspaper concerning the suicide of a member of the Church of Scientology in 2006; links leading to articles concerning the judicial investigation opened in 1995 into the funding of a political party in which the applicant was questioned (proceedings against him were closed by an order discharging him in 2010, and most links were to articles contemporaneous with the opening of investigation and therefore did not mention the outcome of the proceedings) and links leading to articles published in newspapers reporting the criminal hearing during which the applicant was sentenced to imprisonment and judicial supervision for sexual assaults on children under the age of 15. Following Google's rejection of their requests, they turned to the French data protection authority (the CNIL) and sought to have Google ordered to remove the links in question. After the CNIL (also) rejected their claims, they turned to the French Council of State, which initiated the relevant preliminary reference procedure before the CJEU.

${ }^{91}$ The EU data protection law (now the GDPR) does not envisage any general derogation from those prohibitions and restrictions, and any other interpretation would contravene the purpose of ensuring enhanced protection of such data processing. GC and Others judgment (n 6) paras 42-44.

92 'ex ante control of internet pages which are referenced as the result of a search does not fall within the responsibilities or the capabilities [...] of a search engine. The task of the operator of a search engine is, as its title indicates, to search, find, point to and make available, by means of an algorithm that allows information to be found in the most effective manner. Conversely, it is not for the operator of a search engine to monitor, indeed to censure. The operator of a search engine acts for the purposes of the search and reacts for 
and obligations, ${ }^{93}$ the mentioned prohibition and restrictions were held applicable to the operator 'in the context of his responsibilities, powers and capabilities (...), on the occasion of a verification performed by that operator, under the supervision of the competent national authorities, following a request by the data subject'. ${ }^{\prime 4}$ As a result, the establishment of whether the operator meets the exception(s) to the prohibited processing of special categories of personal data (or the restrictions on the processing of personal data relating to criminal convictions and offences) takes place only subsequently to that processing (the indexing and presentation in search results), in response to the data subject's (re)action, such as the filing of a corresponding (delinking) request. In literature, some of the authors observed that such a procedure resembles that of a notice and takedown regarding potentially illegal information stored by hosting intermediaries under the e-Commerce Directive, ${ }^{95}$ and have referred to it specifically in the context of the GC and Others judgment as the 'Notice-and-Delist Mechanism for Sensitive Data'96 or 'notice and takedown' procedure in the realm of Art 9 GDPR. ${ }^{97}$

The next issues which were not addressed under EU law up until the GC and Others judgment were which of the exceptions to the processing of special categories of personal data could apply to search engine operators, and whether there are consequences related to their not being met. ${ }^{98}$ In terms of the currently applicable GDPR, controllers must (in as much as under the earlier Directive) fulfil the data processing principles in Art 5 GDPR and one of the lawful processing grounds and derogations under Arts 6 and 9 GDPR..$^{99}$

the purposes of the de-referencing of a search result (...). By the same token, and as the Commission also emphasises [...] the prohibitions and restrictions [...] cannot apply to an operator of a search engine as though it had itself caused the sensitive data to appear in the internet pages referenced. Logically, the activities of a search engine intervene only after (sensitive) data have been placed online and are secondary in nature'. AG Opinion (n 76) paras 54-55.

93 '(...) specific features of the processing carried out by the operator of a search engine in connection with the activity of the search engine (...) may (...) have an effect on the extent of the operator's responsibility and obligations under those provisions'. GC and Others judgment (n 6) para 45.

${ }^{94} \mathrm{GC}$ and Others judgment (n 6) paras 45-48.

${ }_{95}$ See Art 14(1) Directive 2000/31/EC (n 42).

96 Yuliya Miadzvetskaya and Geert Van Calster, 'Google at the Kirchberg Dock. On Delisting Requests, and on the Territorial Reach of the EU's GDPR' (2020) 6 European Data Protection Law Review 143, 145-146.

97 Jure Globocnik, 'The Right to Be Forgotten is Taking Shape: CJEU Judgments in GC and Others (C-136/17) and Google v CNIL (C-507/17)' (April 2020) 69 GRUR International, 380 <https://doi.org/10.1093/grurint/ikaa002> accessed 30 June 2021.

${ }^{98}$ See $\mathrm{n} 84$.

${ }^{99}$ As specified by the EDPB in its recent Guidelines, unrelated to delisting issues: 'Guidelines $03 / 2020$ on the processing of data concerning health for the purpose of scientific 
In its analysis of the mentioned exceptions, the CJEU found it unlikely that the data subjects would provide prior explicit and specific consent $^{100}$ for the listing of their sensitive data in search results, ${ }^{101}$ and considered two other prescribed exceptions as potentially applicable to search engine operators. The first is where the data were made manifestly public by the data subject. ${ }^{102}$ While the Court did not provide interpretation and further analysis on the mentioned exception, it is considered unlikely to apply in any significant number of cases. ${ }^{103}$ In any event, where such exception should be found to apply, the operators could refuse to delist the data provided that the conditions for lawfulness, ie principles relating to the processing of personal data were satisfied (such as that the data are accurate and up-to-date). ${ }^{104}$ On the other hand, it should be kept in mind that the data subjects may also then invoke their

research in the context of the COVID-19 outbreak', 21 April 2020, 6 (point 15). More specifically, in 2014 the Article 29 Data Protection Working Party (which preceded the current EDPB) issued an Opinion discussing the relationship of comparable provisions in the earlier DPD and in particular on whether the exceptions for processing special categories of personal data exclude the application of the provision on legal bases for the processing of personal data in general: 'If Article 8 is designed as a lex specialis, it should be considered whether it excludes the applicability of Article 7 altogether. If so, it would mean that special categories of personal data can be processed without satisfying Article 7, provided one of the exceptions in Article 8 applies. It is, however, also possible that the relationship is more complex and Articles 7 and 8 should be applied cumulatively. (...) Either way, it is clear that the policy objective is to provide additional protection for special categories of data. Therefore, the final outcome of the analysis should be equally clear: the application of Article 8 , whether in itself or in a cumulative way with Article 7, aims at providing for a higher level of protection to special categories of data'. 'Article 29 Data Protection Working Party, Opinion 06/2014 on the notion of legitimate interests of the data controller under Article 7 of Directive', 95/46/EC, 844/14/EN, WP 217, 9 April 2014, 14.

100 Consent of the data subject means any freely given, specific, informed and unambiguous indication of the data subject's wishes by which he or she, by a statement or by a clear affirmative action, signifies agreement to the processing of personal data relating to him or her. Art 4(11) GDPR. Under Art 9(2)(a) GDPR, the general prohibition of processing special categories of personal data shall not apply where the data subject has given explicit consent to the processing of those personal data for one or more specified purposes, except where Union or Member State law provide that the prohibition referred to above may not be lifted by the data subject.

${ }^{101}$ This may be additionally complicated by the fact that the Member States may override this exception in their legislation. Art 9(2)(a) GDPR. According to the CJEU, the fact that the delisting request was filed in any case signifies the withdrawal of any such consent, in connection with which also noted was that the withdrawal of consent, where no other grounds for processing exist, is a prescribed ground for seeking data erasure. Art 17(1)(b) GDPR. GC and Others judgment (n 6) para 62.

102 Art 9(2)(e) GDPR. This exception from the general prohibition of processing special categories of personal data applies equally to the search engine operator and data publisher (publisher of a web page). GC and Others judgment (n 6) para 63.

103 The manifestly made public exception is unlikely to apply in many cases, since such information would normally be published not by the data subject himself /herself, but by others. Globocnik (n 97).

${ }^{104}$ See in particular Art 5 GDPR (principles relating to the processing of personal data). 
right to objection on grounds relating to their particular situation, as well as the right to erasure, ${ }^{105}$ as examined in the previous section of the paper. Furthermore, the CJEU does not explicitly link the right to object to any of the two prescribed bases for the operator's processing, where the right to object could be invoked in the stricto sensu application of the law. ${ }^{106}$ This was perhaps done intentionally, since it is unlikely that sensitive data could ever be systematically processed by operators under either of the two prescribed bases. In any case, the positive end-result for data subjects according to the analysis is that (as in cases of ordinary data processing) the right to delisting encompasses their objection right on grounds relating to their particular situation (and the related erasure right on account of such an objection) by default, ie regardless of the established legal grounds (exceptions or restrictions) for the listing of their sensitive data in search results. On the other hand, in addition to the general legitimisation of non-routine a posteriori verifications (of exceptions and restrictions), meaning that all sensitive data continue to be listed until the delisting request, even where for those same reasons data subjects could, for example, assert unlawful processing and thereby seek erasure under the GDPR, their request would in certain cases still be denied on account of freedom of information ${ }^{107}$ (as was already established to be the case in the previous section for cases of ordinary data processing). The latter issue will be explored in more detail in the next section of this paper in connection with an analysis of the second possibly applicable exception to legitimise the listing of sensitive data.

\subsubsection{The controlling function of substantial public interest exception/reasons}

The second exception to the prohibited processing of sensitive data that the Court found potentially applicable also for a search engine operator's processing activities is where that processing is necessary for reasons of substantial public interest, on the basis of EU or Member State law, which must be proportionate to the aim pursued, respect the essence of the right to data protection and provide for suitable and specific measures to safeguard the fundamental rights and the interests of the data

\footnotetext{
${ }^{105}$ GC and Others judgment (n 6) paras 64-65.

${ }^{106}$ See $\mathrm{n} 60$.

107 This was exactly the argument provided by AG Szpunar in his Opinion in this case, when he considered that the 'fact that the data on an internet page come within Article 9 of that directive must constitute a circumstance that may allow a request for de-referencing to be refused (...)', especially since the GDPR '(...) recognises a limitation of the right to de-referencing for reasons relating to freedom of expression and information, even if the processing concerns sensitive data'. AG Opinion (n 76) para 98 in connection with para 87.
} 
subject. ${ }^{108}$ In a lack of further analysis by the Court, an interpretation of this exception, which may normally include different important societal goals, might possibly be supported with the prescribed exceptions from the right to erasure. ${ }^{109}$ One such exception is where the processing (ie the continued inclusion of a relevant link in search results displayed following a search query based on the data subject's name) is necessary for compliance with a legal obligation to which the controller is subject or for the performance of a task carried out in the public interest or in the exercise of official authority vested in the controller. In its Guidelines, the EDPB clarified that "content of this exemption makes it difficult to apply to the activity of search engine providers and it may have influence on the decisions of delisting certain results, as the processing of data by search engine providers is based, in principle, on the legitimate interest of the search engine provider.' ${ }^{110}$ In any event, the Court did not specifically examine the mentioned exception further in the context of whether and when such an exception might apply to the operator's specific data processing activities. This examination would be left for the national courts, in observance of the criteria that the Court subsequently provided for assessments of delisting requests relating to sensitive data. In this context, the Court afforded a vital role to the mentioned reasons of substantial public interest exception ${ }^{111}$ in its totality, thus taking into account all the conditions prescribed in that exception. ${ }^{12}$ Therefore, delisting requests should only be denied where it is determined, upon analysis of all the relevant circumstances of the case and the seriousness of the interference for the data subject's privacy and data protection, having regard to reasons of substantial public interest that the inclusion of a relevant link in name-based search queries would be strictly necessary to ensure internet users' freedom of information. Furthermore, this interference

\footnotetext{
${ }^{108}$ Art 9(2)(g) GDPR. A comparable provision in Art 8(4) DPD provided that Member States may enact for reasons of substantial public interest additional exemptions, either by national law or by a decision of the supervisory authority, all subject to the provision of suitable safeguards.

109 This is in particular in light of the earlier noted EDPB interpretation that the operator's overriding legitimate grounds for processing may also include any of the prescribed exceptions to the right to erasure. See $\mathrm{n} 77$.

110 EDPB (n 10) 13 (point 55). For further interpretation, specifically on the (non-)applicability of the exception of performance of a task carried out in public interest or in the exercise of official authority to search engines, see EDPB (n 10) 14-15.

${ }^{111}$ GC and Others judgment (n 6) paras 66, 68 and 75.

112 ie the processing that is necessary for reasons of substantial public interest must be based on EU or Member State law, which must be proportionate to the aim pursued, respect the essence of the right to data protection and provide for suitable and specific measures to safeguard the fundamental rights and the interests of the data subject. Art 9(2)(g) GDPR.
} 
may be particularly serious purely on account of the (sensitive) nature of such data. ${ }^{113}$

It has been argued in literature that instead of invoking the substantial public interest exception (reasons), the Court could have invoked the earlier examined generally applicable freedom of information and expression under the right to erasure. ${ }^{114}$ In connection with this, it should be kept in mind that the right to erasure, as enacted, may always trump unlawful processing to the extent that such processing (ie the inclusion of links into search results) is necessary for exercising the right of freedom of expression and information, which is ultimately an issue left to examination by national courts.

In my opinion, the Court's focus on the substantial public interest exception (reasons) was entirely purposeful. Namely, in an examination of the delisting requests, the substantial public interest exception is possibly the only remaining connection to the otherwise applicable data protection law principles intended to ensure heightened protection of the vulnerable, ie sensitive data. Moreover, the prescribed requirement that it must be based on the law of appropriate quality (ie it must be proportionate, respect the essence of the data protection right and provide safeguards) enables sufficient control to ultimately support at least the ratio legis of stricter protection of such data under data protection legislation, concerns which must also apply in the context of the operator's referencing to such data. ${ }^{115}$ At the same time, the freedom of information of internet users to access such data via a name-based search query systematically remains a crucial element in balancing assessments.

\subsubsection{Substantial public interest, freedom of information and balancing assessment}

According to interpretations by various authors, the CJEU (may have) referred to the freedom of information of internet users as constituting the mentioned substantial public interest. ${ }^{116}$ It appears to be a

\footnotetext{
113 GC and Others judgment (n 6) paras 44 and 67.

114 Globocnik (n 97).

115 As argued by AG Szpunar, '(...) preventing the possible amplification of such data by a search engine is also covered by the ratio legis of Article 8(1) and (5) of Directive 95/46 (...)'. AG Opinion (n 76) para 72. For the entire analysis, see paras 62-74.

116 This is mainly in interpretation of the Court's analysis starting from para 66 (whilst the earlier noted substantial public interest exception is referred to in the earlier para 61 of the judgment). See Miadzvetskaya and Van Calster (n 87) 144; Gabriela Zanfir-Fortuna, 'Key Findings from the Latest "Right To Be Forgotten" Cases' (Future for Privacy Forum, 27 September 2019) https://fpf.org/2019/09/27/key-findings-from-the-latest-right-to-be-forgotten-cases accessed 30 June 2021; Silvia De Conca, 'GC et al v CNIL: Balancing the Right to Be Forgotten with the Freedom of Information, the Duties of a Search Engine Operator'
} 
further matter of interpreting, according to the concrete facts of the case, including the types of sensitive data and publication(s) involved, whether the operator could independently of the publisher be (held) entitled to ensure 'public interest reasons' by including specific links to sensitive data in search results produced in response to name-based search queries, which are in this way made easily available to internet users. Based on the more obvious scenarios, for now such assessments appear to leave room for possible denials of delisting requests where the data were initially published for journalistic (or artistic or literary expression) purposes. ${ }^{117}$ This is only provided that the core of delisting is thereby maintained, ${ }^{118}$ and that by taking into account all the circumstances of the case and other relevant factors as provided by the CJEU, ${ }^{119}$ an assessment is made of the strict necessity to maintain such links in results displayed upon a name-based search query, for the purposes of ensuring easy access to such (sensitive) data to ensure internet users' freedom of information. In this context, relevant national legislation (eg regulating freedom of information and expression) that may support substantial public interest reasons should incorporate the requirements of Art 85 GDPR. ${ }^{120}$

(2019) 5 European Data Protection Law Review 561, 565; Globocnik (n 97). cf Leiser and Schemer, who pose questions on what constitutes substantial public interest and conclude that 'any defence that processing can be legitimised under Article 9(2) is shaky. This leaves Google with the more general exception of the freedom of expression and information. This is provided for in Article 85 of the GDPR which requires Member States to provide exemptions and derogations to Chapter II (which includes Article 9) in order to protect the freedom of expression and information. Indeed, it is the right to freedom of expression that is weighed against the rights of the data subject in de-indexing cases. But whether Google can rely by default on the freedom of expression to process special categories of personal data remains uncertain'. Leiser and Schermer (n 89).

117 In relevant national proceedings, the sensitive data concerned appear to have mostly been published for journalistic purposes. See $n 90$.

118 ie the maintained delineation between the different processing activities of the publisher and operator and the possible different consequences thereof for data subjects.

119 'In any event, when the operator of a search engine receives a request for de-referencing, he must ascertain, having regard to the reasons of substantial public interest referred to in Article 8(4) of Directive 95/46 or Article 9(2)(g) of Regulation 2016/679 and in compliance with the conditions laid down in those provisions, whether the inclusion of the link to the web page in question in the list displayed following a search on the basis of the data subject's name is necessary for exercising the right of freedom of information of internet users potentially interested in accessing that web page by means of such a search, a right protected by Article 11 of the Charter. While the data subject's rights protected by Articles 7 and 8 of the Charter override, as a general rule, the freedom of information of internet users, that balance may, however, depend, in specific cases, on the nature of the information in question and its sensitivity for the data subject's private life and on the interest of the public in having that information, an interest which may vary, in particular, according to the role played by the data subject in public life (see, to that effect, judgment of 13 May 2014, Google Spain and Google, C-131/12, EU:C:2014:317, paragraph 81)'. GC and Others judgment (n 6) para 66.

${ }^{120}$ See $\mathrm{n} 57$ on Art 85(1) GDPR. For processing carried out for journalistic purposes or for the purpose of academic artistic or literary expression, Member States shall provide for 
In my opinion, nothing in the GC and Others judgment, despite the clear and continued delineation between the original publisher's and search engine's processing activities prevents the conclusion that substantial public interest reasons, where the data were originally published for journalistic purposes (or for the purposes of artistic and literal expression) could also be invoked by data publishers for the purposes of ensuring a comprehensive balancing assessment that is specific to delisting cases under CJEU jurisprudence (eg as regards the circumstances of publication in the particular case). ${ }^{121}$ With respect to the balancing assessment, what should be seen as a significant development is that in contrast to the Google Spain judgment, the Court provides clear references to Articles 11 and 52(1) of the Charter on the freedom of information and limitations to the exercise of rights and freedoms under the Charter. ${ }^{122}$ Though this approach appears mainly prompted by an analysis of the new GDPR provision on limitations of the right to erasure due to freedom of expression and information, ${ }^{123}$ it 'feels' more like a rectified or at the very least expanded balancing approach from the Google Spain judgment. ${ }^{124}$ In this connection, while also unreferred to in the Google Spain judgment, what is to be noted is the Court's pointing to the established principle in its case law on data protection as a right that is not absolute and requires balancing, ${ }^{125}$ which is now expressly included in recital 4 of the GDPR. ${ }^{126}$

exemptions or derogations from Chapter II (principles), Chapter III (rights of the data subject), Chapter IV (controller and processor), Chapter V (transfer of personal data to third countries or international organisations), Chapter VI (independent supervisory authorities), Chapter VII (cooperation and consistency) and Chapter IX (specific data processing situations) if they are necessary to reconcile the right to the protection of personal data with the freedom of expression and information. Art 85(2) GDPR.

${ }^{121}$ AG Szpunar highlighted the role of the publisher's freedom of expression where relevant data were published for journalistic (or artistic or literary expression) purposes and concluded that: '(... ) when the right to respect for privacy and the right to protection of data under Articles 7 and 8 of the Charter, on the one hand, are weighed against the right of the public to access the information at issue, on the other hand, the fact that that information comes from the pen of a journalist or constitutes an artistic or literary expression is a factor that must be taken into account', and that ' (...) when weighing up the interest of potentially interested internet users in having access to an internet page via a search conducted on the basis of the data subject's name against that data subject's fundamental rights under Articles 7 and 8 of the Charter, it is also necessary to take into account the freedom of expression and freedom to receive and impart information of publishers and internet users guaranteed by Article 11 of the Charter'. AG Opinion (n 76) paras 88-89. Additionally, see paras 68 and 92 .

${ }^{122}$ GC and Others judgment (n 6) paras 57-58, 66, 68-69, 75, 79.

${ }^{123}$ Art 17(3)(a) GDPR.

${ }^{124}$ For critical analyses of the balancing approach employed in the Google Spain judgment, see $\mathrm{n} 20$.

125 eg joined cases C-92/09 and C-93/09 Volker und Markus Schecke GbR (C-92/09) and Hartmut Eifert (C-93/09) $v$ Land Hessen ECLI:EU:C:2010:662. See especially paras 47-52.

${ }^{126}$ GC and Others judgment (n 6) para 57. 
Additionally, and what in my view is the most important development since the Google Spain judgment, the Court referred to the relevant ECtHR case law concerning press matters in the context of assessing the freedom of information of internet users. That issue was approached in its analysis of questions referred for a preliminary ruling concerning the listing of personal data relating to criminal convictions and offences. In its analysis, the Court firstly confirmed that such data also include published information as regards the proceedings brought against the data subject, which concern the earlier procedure stages and are no longer correct (ie outdated/inaccurate data). ${ }^{127}$ Secondly, it affirmed that evaluation of delisting requests also for such data must include a verification of earlier noted substantial public interest reasons. ${ }^{128}$ Finally, the balancing assessment where the freedom of information of internet users is concerned should include regard for relevant ECtHR case law in press matters, which includes consideration of the users' right to access information on a given topic and carry out research into past events. ${ }^{129}$ As a result, a list of elements that should be examined in assessments of relevant delisting requests includes: the nature and seriousness of the offence, the progress and outcome of the proceedings, the time elapsed, the part played by the data subject in public life and his past conduct, the public interest at the time of the request, the content and form of the publication, and the consequences of publication for the data subject. ${ }^{130}$

While from the judgment it is not precisely clear whether the aid of the ECtHR balancing criteria in press matters might apply to a wider scope of cases and circumstances where the data have been published for journalistic purposes, ${ }^{131}$ the EPDB seems to take that view. It more recently referred to the balancing developed in the ECtHR case law in press matters to apply in assessments of delisting requests, in addition to the balancing criteria developed by the CJEU in the Google Spain judgment. ${ }^{132}$ In this sense, the earlier voiced criticisms of the Court's lack of regard for the ECtHR balancing criteria in the Google Spain judgment have certainly been appeased. ${ }^{133}$

\footnotetext{
${ }^{127}$ Such data also concern 'information relating to the judicial investigation and the trial and, as the case may be, the ensuing conviction', 'regardless of whether or not, in the course of those legal proceedings, the offence for which the individual was prosecuted was shown to have been committed'. GC and Others judgment (n 6) paras 72, 79.

${ }^{128}$ GC and Others judgment (n 6) para 75.

129 ibid, para 76. The balancing entailed is between the right to privacy and the freedom of expression and information under the European Convention on Human Rights (Arts 8 and 10).

${ }^{130}$ GC and Others judgment (n 6) para 77.

${ }^{131}$ See $\mathrm{n} 121$ for related arguments by AG Szpunar.

${ }^{132}$ EDPB (n 10) 9 (point 30). Additionally, see 12 (point 50).

${ }_{133}$ See eg Frantziou (n 20); Peguera (n 20).
} 


\subsubsection{Consequences of the judgment}

Opinions vary, rightly, on whether or not the GC and Others judgment ensured the overall protection of data subjects under data protection law. ${ }^{134}$ On that note and in addition to the findings from the previous section, the analysis has shown that there appear to be no consequences for the search engine operator under EU law even in cases where the prescribed exceptions and restrictions as regards sensitive data processing were not met, as well as in cases where the conditions of lawfulness were not met, all until a mandatory balancing of rights and interests is performed. On the other hand, as observed earlier, data subjects can always invoke delisting on the basis of their particular situation. And finally, the operators must in any case establish, having regard to reasons of substantial public interest and in line with all the prescribed specific conditions, if the inclusion of such links in the context of a specific search query based on the data subject's name is strictly necessary for ensuring the freedom of information of internet users. In other words, this means that the delisting regime set out under the Google Spain judgment continues to apply (and thus the operator's practices as of 2014) also for cases where delisting requests relate to sensitive data, although with two crucial differences. First, the very nature of such data being processed by search engine operators could constitute, possibly by default, particularly serious interference in the data subject's rights. Secondly, the reasons of substantial public interest, which must be envisaged in EU or Member States' law of a prescribed quality, need to support the inclusion of links to the sensitive data in search results following a narrow namebased query as strictly necessary for protecting the freedom of information of internet users who wish to easily access such data in that way. Finally, irrespective of the qualification of data as ordinary or sensitive, the comprehensive balancing assessment as regards the data published for journalistic purposes needs to incorporate the relevant ECtHR balancing criteria.

\footnotetext{
${ }^{134}$ For example, Globocnik considers that the overall level of protection was lowered, since 'as long as a data subject does not request that sensitive data pertaining to her be de-referenced, the search engine operator can lawfully process such data, even if no exception under Art. 9(2) GDPR is applicable. Unlike in other cases of data processing, data subjects hence have to make an effort to have their interests protected'. Globocnik (n 97). Zalnieriute argued that the judgment 'extended the grounds upon which EU citizens can request a search engine to de-reference search results'. Monika Zalnieriute, 'To Forget, But Not Forgive: Why the CJEU's Latest Ruling on Google and the "Right to Be Forgotten" Is Not at All a Win for US Tech Giants' (EJIL:Talk! 29 November 2019) <www.ejiltalk.org/to-forgetbut-not-forgive-why-the-cjeus-latest-ruling-on-google-and-the-right-to-be-forgotten-is-notat-all-a-win-for-us-tech-giants/> accessed 30 June 2021. Both authors are correct in their interpretation of the matters in focus.
} 


\section{A novel duty to rearrange search results: in search of 'more balance'?}

Particular emphasis should be placed on the created new, in my opinion exceptional, duty of search engine operators in cases where delisting requests are not accepted due to the prevailing interest of the public to access such data, despite their being no longer accurate. That duty consists of adjusting, ie rearranging, search results so that 'the overall picture it gives the internet user reflects the current legal position, which means in particular that links to web pages containing information on that point must appear in first place on the list'. ${ }^{135}$ This is to be done at the latest upon examination of the delisting request. However, while the Court specifically links that novel duty with delisting requests in relation to published information relating to criminal proceedings brought against the data subject, concerning an earlier stage of the proceedings and no longer corresponding to the current situation, it is unclear whether this duty should extend to all rejected requests for delisting, in particular concerning other sensitive data (ie special categories of personal data) that are currently inaccurate. While lacking a legal basis therefor in the judgment itself, it could be argued that such rearrangement is in principle the implementation of the GDPR data accuracy principle. ${ }^{136}$ On the other hand, the consequence of such a deduction is potentially a far broader set of qualifying circumstances and personal data, and the rearrangement would in any case represent a significant change to the search engine's processing (business) operations. Should the same duty, for example for the same reasons of accuracy, apply in cases of denied delisting requests as regards all personal data and only where search results (following a narrow query based on the data subject's name) show that the more accurate data have been published? What exactly are the criteria for establishing whether such a duty should or should not apply? In that context, Globocnik masterfully summed up a whole set of currently unresolved issues, eg:

who is competent to decide whether the 'overall picture' is correct, and what is the search engine operator obliged to do if no links reflecting the current position that could be displayed in search results exist? Also, as simply sorting search results in chronological order might not always suffice to leave a 'correct impression', this rule presupposes that the search engine understands the content of the data listed in the search results. This will require additional inputs on the side of search engine operators in the form of workers and/or algorithms sorting search results in such a way as to create a correct overall picture,

${ }^{135}$ GC and Others judgment (n 6) para 78.

${ }^{136} \operatorname{Art~5(1)(d)~GDPR.~Globocnik~(n~97).~}$ 
and might set an end to the usage of algorithms that sort search results based on the (perceived) relevance for the internet user. This could create considerable challenges for search engine operators and possibly even affect the core of their business models. ${ }^{137}$

Where the focus remains on search engines' 'pivotal role as gatekeeper on the Web', which 'establishes them as narrators with a rather authoritative voice, ${ }^{138}$ concerns might arise that following the novel, arguably restricted, duty of rearranging search results the delisting right is approaching the contentious ${ }^{139}$ qualification of the right to construct one's own narrative. ${ }^{140}$ While taking into account that all analysis in this paper is made from a purely legal angle, to those concerns I would firstly respond with a small digression, by describing my own perception, as that of a voracious user of the search engine and well, a human being trying to put myself in the shoes of another. 'Well, it is only fair. Where data protection was not able to ensure protection, the CJEU found a reasonable way to make it feel less bitter'. While data accuracy reasons, in particular where sensitive data are concerned, could indeed call for the establishment of the new duty to a broader set of cases, any justification of future extension in particular for data accuracy reasons is prone to impact the tenets of the sui generis delisting right discussed in this paper. And that right only lives on account of the necessary contouring of data protection legislation to the context of search engine's responsibilities, powers and capabilities. Therefore, whatever the future approach, I believe that the Court will not shift away from its clear awareness of the impact that any potential further extension would have on a search engine's essential functioning as an information intermediary, a concern

137 Globocnik (n 97). cf Leiser and Schermer, who provide a warning that should effects of the judgment undermine the operator's business model, it might claim an infringement of their freedom to conduct a business guaranteed under Art 16 of the Charter. Leiser and Schermer (n 89).

${ }^{138}$ PEI Korenhof, 'Let's Forget about It: The Web of Problems for the Right to Be Forgotten' (Doctoral thesis, Tilburg University, 2020) $313<$ https://research.tilburguniversity. edu/en/publications/lets-forget-about-it-the-web-of-problems-for-the-right-to-be-forg> accessed 30 June 2021.

${ }^{139}$ In this respect, Google argues that the 'RTBF is not a right to rewrite history, erase certain parts of a professional career or build a tailored past', and supports its arguments with Spanish and other national jurisprudence (fn 18): 'Submission to the public consultation on Guidelines 5/2019 on the criteria of the Right to be Forgotten in the search engines cases under the GDPR (part 1)' (EDPB, 6 February 2020) $10<$ https://edpb.europa.eu/ sites/edpb/files/webform/public_consultation_reply/google_response_to_right_to_be_forgotten_edpb_open_consultation_1.pdf> accessed 30 June 2021.

${ }^{140}$ Noam Tirosh, 'Reconsidering the "Right to be Forgotten": Memory Rights and the Right to Memory in the New Media Era' (2017) 39 Media Culture \& Society 644, 645. 'What people really ask Google, or any other search engine, is not to forget anything, but to be in charge of their narrativization process which involves both remembering and forgetting that coalesce in their memory's construction practices'. ibid 653. 
which has in any case been carefully considered and preserved as of the establishment of the right to delisting. ${ }^{141}$

\section{Concluding remarks}

The CJEU jurisprudence has so far kept the main postulates of the sui generis right to delisting by clearly delineating between the different processing activities of the publisher and the search engine operator and the possible different consequences thereof for data subjects, which for reasons of effective and complete protection of data subjects opened the door for granting delisting requests against operators also where relevant data were not previously or simultaneously removed from source web page and where they were lawfully published. Once the search engine operator who in principle exercises its essential functions by the unmonitored indexing of all content on the web was declared a controller, it was clear that the personal data protection right in connection with that function could only start to apply upon the data subject's filing of the delisting request. Furthermore, in doing so, it would require adjustments to the context of the search engine's responsibilities, powers and capabilities. In this setting, whilst never excluding the fact that data protection is not absolute, it is on account of the resulting considerable contouring of EU data protection legislation, which does not put the operator's core function at risk, that the usual question about whether the data protection right may be ensured effectively and completely, should rather be rephrased as whether it may be ensured 'closely enough'. Based on the analysis in this paper, I think it may. However, there are a few caveats.

With the enactment in the GDPR of the freedom of information and expression exception from the duty of erasure, operators are provided with a priori significant leeway in delisting cases also where their processing activities are not lawful strictly under data protection legislation. While the assessment and balancing criteria provided in relevant CJEU jurisprudence necessarily do complement the currently unclear details as to the role and application of that exception in the context of delisting, the assessment and interpretation of relevant national legislation in delisting cases, where published information falls in the scope of journalistic exception, should in my opinion incorporate the requirements

\footnotetext{
${ }^{141}$ According to Kun, the Court's 'case-law on search engines can be interpreted as proper reconciliation of the freedom to conduct business with the right to data protection in Google Spain and GC and Others. The Court does not directly establish a relationship between the tailored liability of search engines and this freedom in its case-law. Nevertheless, this would be embedded in the phrasing of 'within the framework of its responsibilities, powers'. This type of responsibility would be proportionate as long as it is restricted to the only limited business models rather than broad exceptions. Eyup Kun, 'Inherent Role of the Freedom to Conduct a Business under GDPR: The Tailored Liability of Search Engines' (2020) < ssrn. com/abstract_id=3933338> accessed 1 October 2021.
} 
of Art 85 GDPR. In any event, further interpretations of the freedom of information and substantial public interest exception (reasons) are to be resolved through Member States' national case law, in the interpretation of relevant national legislation and, where applicable, supported by relevant ECtHR case law in press matters for the purposes of establishing the (non-)prevailing freedom of information of internet users.

Whether referred to as legitimate interest, compelling legitimate grounds, overriding legitimate grounds, or substantial public interest, all of the analysed data processing grounds, exceptions thereto, and the roles in the assessment of delisting requests have freedom of expression and information concerns as a common denominator when the data published falls in the scope of journalistic exception. In that light, Google's recently declared compelling legitimate ground of 'public interest in accessing and imparting information', which may be interpreted to include both the freedom of internet users to access information and the freedom of expression for publishers imparting information, comes as no surprise. ${ }^{142}$ Hence a further matter to be explored is whether, in addition to the interest of internet users (the public) to easily access relevant data via a name-based search query, the balancing assessment should also incorporate, and to what extent, the legitimate interests of data publishers who placed the data online for journalistic purposes (or the purpose of artistic or literary expression) and who have an interest in disseminating them via search-engine referring activities. ${ }^{143}$ 'In real life', some form of engaging publishers has been taking place upon Google's implemented practice, which, following a notification of delisted URLs, ${ }^{144}$ provides the publishers with an opportunity to request their reinstatement with the supporting information on why such reinstatement would be in the public interest. ${ }^{145}$

\footnotetext{
${ }^{142}$ Submission (n 139) 10.

143 ibid, 15 and cited case law (fn 26).

${ }^{144}$ Google, 'EU Privacy Removal. Personal Information Removal Request Form' <www. google.com/webmasters /tools /legal-removal-request?complaint_type=rtbf\&visit_ id $=637202230061146146-20083139 \& r d=1>$ accessed 30 June 2021. While detailed analysis of such practices falls outside the scope of this paper, it should be noted that they were more recently challenged and that they appear to be a matter of contention between Google and the data protection authorities on data protection grounds. For more details, see Article 29 Data Protection Working Party (n 9) 10 (point 23); EDPB (n 10) 6 (point 12); Submission (n 139) 5-8 (notices to webmasters) and cited case law; 'Swedish Authority for Privacy Protection Imposes Administrative Fine on Google' (Swedish Authority for Privacy Protection, 11 March 2020) <https://www.imy.se/en/news/the-swedish-data-protection-authority-imposes-administrative-fine-on-google/> accessed 30 June 2021. For a recent detailed analysis in literature, see David Erdos, 'Disclosure, Exposure and the 'Right to be Forgotten 'after Google Spain: Interrogating Google Search's Webmaster, End User and Lumen Notification Practices' (2020) 38 Computer Law \& Security Review <https://doi.org/10.1016/j.clsr.2020.105437>.

145 Google, 'EU Privacy Removal. Web Search Removal under Data Protection Law in Europe' $<$ https://www.google.com/webmasters/tools/eu-privacy-webmaster> accessed 30 June 2021.
} 
While any definitive approach thereto is currently unfeasible on account of a lack of EU-law harmonisation in the area of reconciling privacy and data protection rights with the freedom of expression and information, ${ }^{146}$ a close eye is needed on the approaches taken by national courts and thus on the emerging jurisprudence in Member States. The CJEU's confirmation that the interest of the public in accessing relevant data via a specific search engine query might vary (also) in different EU Member States adds another layer to this tangled issue ${ }^{147}$ and it is in any case not unlikely that the Court's balancing of rights and freedoms under the Charter (as supported by relevant ECtHR case law) will be revisited sometime in the future. ${ }^{148}$ In any event, the issue of whether the publisher has the right to publish and maintain published information online (which, arguably, in many cases it would have precisely due to its freedom of information) as well as to make it available to the public via search-engines should, by the very essence of the right to delisting, always be clearly discerned from the issue of whether links to such published information need to be included in the search engine's results, upon a restricted and specific name-based search query.

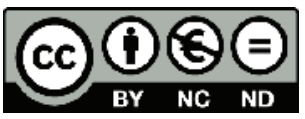

This work is licensed under the Creative Commons Attribution - Non-Commercial - No Derivatives 4.0 International License.

Suggested citation: N Gumzej, “The Right to be Forgotten' and Sui Generis Controller in the Context of CJEU Jurisprudence and the GDPR' (2021) 17 CYELP 127.

\footnotetext{
${ }^{146}$ In respect to the challenges in national implementation of the relevant Art 85(2) GDPR on reconciling the right to data protection with the right to freedom of expression and information, see, eg, Commission, 'Communication from the Commission to the European Parliament and the Council. Data protection as a pillar of citizens' empowerment and the EU's approach to the digital transition - two years of application of the General Data Protection Regulation' COM (2020) 264 final 1, 7; and notifications by EU Member States under Art 85(3) GDPR: 'EU Member States notifications to the European Commission under the GDPR', <https://ec.europa.eu/info/law/law-topic/data-protection/data-protection-eu/ eu-countries-gdpr-specific-notifications_en> accessed 30 June 2021. For a more recent detailed analysis in literature, see: David Erdos, 'Special, Personal and Broad Expression: Exploring Freedom of Expression Norms under the General Data Protection Regulation' (2020) <ssrn.com/abstract_id=3565385> accessed 1 October 2021.

147 Google LLC (n 28). Analysis of this judgment, however, falls outside the scope of this paper.

${ }^{148}$ As commented by Jääskinen: 'Even after the judgments (...), there is still need for further clarification. The balancing operation between the fundamental rights involved is complicated, difficult and far from self-evident'. Nilo Jääskinen, 'Google Spain and Google: Not to Be Forgotten!' in Gavin Barrett, Jean-Philippe Rageade, Diana Wallis and Heinz Weil (eds), The Future of Legal Europe: Will We Trust in It? (Springer/Cham, 2021) 393, 411.
} 